\title{
High-Impact Details of Play and Movements in Female Basketball Game
}

\section{(우(1) $(9)$}

\author{
Authors \\ Yasuharu Nagano' ${ }^{1 D}$, Shogo Sasaki², Yui Shimada ${ }^{2}$, Takeshi Koyama $^{3}$, Hiroshi Ichikawa ${ }^{4}$
}

\author{
Affiliations \\ 1 Department of Sports and Health Science, Japan \\ Women's College of Physical Education, Tokyo, Japan \\ 2 Faculty of Health Sciences, Tokyo Ariake University of \\ Medical and Health Sciences, Tokyo, Japan \\ 3 Sports Medical Science Research Institute, Tokai \\ University, Kanagawa, Japan \\ 4 Department of Health and Sports, Niigata University of \\ Health and Welfare, Niigata, Japan
}

Key words

measurement, musculoskeletal, quantitative study

$\begin{array}{ll}\text { received } & 10.09 .2020 \\ \text { revised } & 06.11 .2020 \\ \text { accepted } & 11.11 .2020\end{array}$

Bibliography

Sports Medicine International Open 2021; 5: E22-E27

DOI 10.1055/a-1309-3085

ISSN 2367-1890

(c) 2021. The Author(s).

This is an open access article published by Thieme under the terms of the Creative Commons Attribution-NonDerivative-NonCommercial-License, permitting copying and reproduction so long as the original work is given appropriate credit. Contents may not be used for commercial purposes, or adapted, remixed, transformed or built upon. (https://creativecommons.org/ licenses/by-nc-nd/4.0/)

Georg Thieme Verlag KG, Rüdigerstraße 14,

70469 Stuttgart, Germany

\author{
Correspondence \\ Yasuharu Nagano \\ Department of Sports and Health Science \\ Japan Women's College of Physical Education \\ 8-19-1, Kitakarasuyama \\ 157-8565 Setagaya-ku, Tokyo \\ Japan \\ Tel.: + 81-3-3300-5437, Fax : + 81-3-3300-5437 \\ nagano323@gmail.com
}

\section{ABSTRACT}

This study aimed to identify the high-impact details of play and movements with higher acceleration and their frequency during a female basketball match. Trunk acceleration was measured during a simulated basketball game with eight female players. The extracted instance was categorized, which generated at $>6$ and $8 \mathrm{G}$ resultant accelerations using a video recording and an accelerometer attached to the players' trunk, as details of play and movements. The frequency and ratio of the details of play and movements regarding all detected movements were calculated. A total of 1062 and 223 play actions were detected for the resultant acceleration thresholds of $>6$ and $8 \mathrm{G}$, respectively. For these acceleration thresholds, in terms of details of play, positioning on the half-court was the most frequently observed ( 29.6 and $23.8 \%$, respectively). In terms of movements, deceleration was the most frequently detected movement ( 21.5 and $23.3 \%$, respectively), followed by landing ( 7.6 and $15.7 \%$, respectively). Deceleration during positioning on the half-court and defense as well as landing mostly after a shot were detected as high-impact frequent basketball-specific movements. The results also showed that characteristics of movements or playing style and playing position may have an effect on acceleration patterns during a basketball game.

\section{Introduction}

Basketball is a popular team sport and has gained significant interest from sport science researchers over the years. During a 40-min basketball game, players actively cover a distance of 5-6 km, involving repeated shuffling, jump-landing, and sprinting; all of which warrant the classification of basketball as a high-intensity intermittent sport [1]. Meanwhile, basketball players can experience severe injuries, especially in the ankle and knee [2]. One of the common acute injuries is that of the anterior cruciate ligament, especially in female high school athletes [3]. Overuse injuries of the knee are 
also relatively common in basketball [4]. An increase in the mechanical load owing to specific movement can induce acute injuries [5], or the accumulation of mechanical load from repetitive movements can induce overuse injuries [6]; it is therefore essential to examine its effects on athletic performance and the occurrence of injuries during high-intensity movements.

The mechanical load experienced by an athlete during training and basketball games can be further categorized as either internal or external load, also known as physiological or biomechanical load [7]. Measures of internal (physiological) load include oxygen uptake, heart rate, blood lactate, and RPE; whereas those of external (biomechanical) load include the joint contact force and muscletendon force. These measures can be obtained using various devices in a laboratory-based environment, but are often difficult to collect during live sports events. Representative external load measures are often based on data obtained from GPS devices, which can measure variables such as running distance and velocity, or other physiologically relevant proxies for energy consumption [7]. However, accelerations and decelerations come at a greater energetic cost than maintaining a constant speed; they also induce a higher biomechanical load on the musculoskeletal system [8]. As such biomechanical loads cannot be estimated from distance or velocity data, GPS devices must also be able to quantify acceleration and deceleration. However, the accuracy of GPS-based acceleration signals remains limited [9]. Therefore, acceleration data measured using an accelerometer have been used as an external biomechanical index [10-12]. Recently, although "player load" has been used as an index of measured acceleration in basketball $[13,14]$, it is unknown what type of movements show high acceleration and are reflected by index.

No unified view has been obtained on an index of acceleration. Peak resultant acceleration (PRA) is an index measure reflecting high-impact movements, gender differences, and stiff cutting movements [15]; it is also correlated with ground reaction force [11]. In volleyball, PRA also reflects individual differences in jumping and non-jumping movements [10]; whereas in badminton, the frequency and details of high-impact movements were estimated using PRA [16]. In addition, examining each directional acceleration could show characteristics of movements. In basketball, quantifying the frequency and details of high-impact movements while playing could help in estimating the biomechanical load.

This study aimed to identify details of play and movements with high impact showing greater resultant acceleration and the frequency of these movements during a female basketball match. We hypothesized that defense reaction to opponents and shot with landing are details of play with high impact showing greater accelerations and that deceleration and landing are frequently detected high-impact movements.

\section{Materials and Methods}

\section{Participants}

In total, eight teenage female basketball players [age, $16.1 \pm 0.6$ years; body mass, $53.6 \pm 6.3 \mathrm{~kg}$; height, $159.8 \pm 4.8 \mathrm{~cm}$; years of experience, $5.9 \pm 1.6$ years (mean \pm SD)] were recruited for this experiment. The competition level of participants was set at prefectures ranking 4th-8th in Japan. The playing positions of participants were: guard $(n=2)$, shooting guard $(n=1)$, guard/forward $(n=1)$, forward $(n=2)$, and center $(n=1)$. Physical evaluations were conducted, which provided the basis for inclusion and exclusion criteria. Players were excluded if they had a history of severe musculoskeletal injury or if they suffered from any musculoskeletal injury within the past three months, as well as any disorder interfering with sensory input, musculoskeletal function, and motor function. Before the start of the study, all participants and their legal guardians provided written informed consent according to the requirements of the ethical review board of the authors' affiliation. The study meets the ethical standards of the journal [17].

\section{Measurements}

Linear acceleration was measured using a lightweight, triaxial accelerometer with a full-scale range of \pm 16 G (SS-WS1201; Sports Sensing, Fukuoka, Japan). The accelerometer was secured to the upper back of the participant using an exclusive vest with compressive innerwear that did not limit upper or lower limb movements [16]. The three axes of the accelerometer were aligned with the anatomical axes of the participants (i. e., the x-axis was aligned mediolaterally, the $y$-axis vertically, and the z-axis anteroposteriorly). Acceleration was measured at a frequency of $200 \mathrm{~Hz}$ and saved in the built-in memory of the accelerometer. The axial direction of the accelerometer was set at $+1 \mathrm{G}$, indicating acceleration due to gravity.

Acceleration measurements were obtained during a $5 \times 5$ basketball match of two 10-min periods (exact total duration, 22 mins $39 \mathrm{~s}$ ), using the same team composition throughout. The match was conducted with two additional players, no-timeout, and nosubstitution, and free throw was permitted. After the experiment, raw data from the accelerometer were downloaded into a database for later analyses. We also recorded the match using two digital video cameras (HDR-CX590V; Sony, Tokyo, Japan) with a frame rate of $60 \mathrm{fps}$, placed on a balcony on the second floor at the back of the goals. We recorded the participants' movements throughout the match using panning motions to cover all participants during the match. All videos were recorded in AVCHD format at a high definition (1080i). A light pulse was used at the start of the measurement to synchronize the accelerometer data with the video sequence.

The resultant acceleration (G) was calculated from the acceleration data. A customized tagging application (Sports Sensing, Fukuoka, Japan) was used to detect instances at which $>6$ and $>8 \mathrm{G}$ of resultant acceleration were generated during the match. Using the Dartfish software (Connect Plus; Dartfish, Fribourg, Switzerland), video sequences corresponding to the time stamps of the $>6$ and $>8$ $G$ resultant accelerations were extracted and fitted with the time of detected acceleration data. The above acceleration thresholds were temporarily used to examine the ratio of corresponding detected details of play and movements. We categorized the extracted instance as details of play and movements based on $>$ Table 1 . For each acceleration threshold, the frequency (case/min) and the ratio of the detected details of play and movements was calculated. Categorization was performed by two researchers who needed to reach a unanimous decision; if they disagreed, other researchers were consulted to obtain a consensus and final decision. Additionally, the top seven basketball-specific movements, pair of movements and de- 
tails of play observed $>6 \mathrm{G}$, were summarized, and the average resultant and each directional acceleration were calculated. In vertical acceleration, a positive value indicates an upward direction, whereas in anteroposterior acceleration, it indicated a posterior direction. For mediolateral acceleration, absolute values were used to eliminate the influence of the dominant hand.

\section{Statistical analysis}

The $95 \%$ confidence interval was calculated for all frequencies using the following formula: movement rate $\pm 1.96 \times$ [movement rate/ square root (number of movements)] [18] to evaluate differences among the identified details of play and among the detected movements. We also compared the resultant and directional acceleration (mediolateral, vertical, and anteroposterior) of the top seven basketball-specific movements using two-way ANOVA (movements $x$ subjects) to examine the main effect of movements and interaction, along with Bonferroni correction as a post hoc test for the variables with significant main effects of movements. To assess the number of cases required to determine significant differences of two-way ANOVA for the top seven basketball-specific movements, a power analysis was performed at $f=0.4$ and $p=0.05$, power $=0.8$, numera-

- Table 1 Categorization of details of play and movements.

\begin{tabular}{|l|l|}
\hline Details of play & Movements \\
\hline Positioning on half court & Deceleration \\
\hline Running on full court & Landing \\
\hline Defense & Cutting \\
\hline Shot & Take-off \\
\hline Pass & Lunging \\
\hline Pass catch & Sidesteps \\
\hline Rebound & Stopping \\
\hline Shot block & Physical contact \\
\hline Dribbling & Etc. (including running) \\
\hline Etc. & Unknown \\
\hline Unknown & \\
\hline
\end{tabular}

tor $\mathrm{df}=42$, and number of groups $=56$. The analysis showed that a frequency of 209 was required to achieve sufficient statistical power to detect significant differences between movement types.

\section{Results}

A total of 1062 and 223 details of play were detected for the resultant acceleration thresholds of $>6$ and $>8 \mathrm{G}$, respectively ( $\triangleright$ Table 2 ). For both acceleration thresholds ( $>6$ and $>8 \mathrm{G}$ ), positioning on the half-court ( 29.6 and $23.8 \%$, respectively), running on the full court ( 25.8 and $22.4 \%$, respectively), and defense (16.5 and $18.8 \%$, respectively) were the most frequently observed details of play. The ratio and frequency of detected movements at each resultant acceleration threshold ( $>6$ and $>8 \mathrm{G}$ ) are shown in $>$ Table 3 . Deceleration was the most frequently detected movement at both acceleration thresholds ( 21.5 and $23.3 \%$, respectively), followed by landing (7.6 and $15.7 \%$, respectively), the ratio of which was increased with increasing threshold.

The seven most common basketball-specific movements generating > $6 \mathrm{G}$ were deceleration during positioning on the halfcourt, deceleration during defense, cutting during positioning on the half-court, landing during a shot, lunging during a pass, sidesteps during defense, and cutting during defense. The descriptive statistics of the resultant mediolateral, vertical, and anteroposterior accelerations for the seven most common basketball-specific movements are shown in $\triangleright$ Table 4 . The two-way ANOVA summary for movements and subjects as factors for each resultant acceleration threshold are presented in > Table 5. Movements alone showed only a significant main effect in mediolateral acceleration, whereas significant interactions were observed in all accelerations. In mediolateral acceleration, the post hoc test showed that "sidesteps during defense" was significantly higher than other basketball-specific movements ( $p<0.001$ for "deceleration during positioning on the half-court," "deceleration during defense," "cutting during positioning on the half-court," and "landing during a shot;" $p<0.01$ for "cutting during defense" and $p<0.05$ for "lunging dur-

- Table 2 Details of play generated $>6$ and 8 G during basketball game.

\begin{tabular}{|c|c|c|c|c|c|c|}
\hline \multirow[b]{2}{*}{ Movement } & \multicolumn{3}{|c|}{$>6 \mathrm{G}$} & \multicolumn{3}{|c|}{$>8 \mathrm{G}$} \\
\hline & $\begin{array}{l}\text { Counts } \\
\text { (cases) }\end{array}$ & $\begin{array}{l}\text { Ratio } \\
\text { (\%) }\end{array}$ & $\begin{array}{l}\text { Frequency (cases/min) } \\
95 \% \text { C.I. }\end{array}$ & $\begin{array}{l}\text { Counts } \\
\text { (cases) }\end{array}$ & $\begin{array}{l}\text { Ratio } \\
\text { (\%) }\end{array}$ & $\begin{array}{l}\text { Frequency (cases/min) } \\
95 \% \text { C.I. }\end{array}$ \\
\hline $\begin{array}{l}\text { Positioning on the } \\
\text { half-court }\end{array}$ & 314 & 29.6 & $1.73(1.54-1.93)$ & 53 & 23.8 & $0.29(0.21-0.37)$ \\
\hline Running on full court & 274 & 25.8 & $1.51(1.33-1.69)$ & 50 & 22.4 & $0.28(0.20-0.35)$ \\
\hline Defense & 175 & 16.5 & $0.97(0.82-1.11)$ & 42 & 18.8 & $0.23(0.16-0.30)$ \\
\hline Shot & 63 & 5.9 & $0.35(0.26-0.43)$ & 28 & 12.6 & $0.15(0.10-0.21)$ \\
\hline Pass & 53 & 5.0 & $0.29(0.21-0.37)$ & 16 & 7.2 & $0.09(0.05-0.13)$ \\
\hline Pass catch & 35 & 3.3 & $0.19(0.13-0.26)$ & 6 & 2.7 & $0.03(0.01-0.06)$ \\
\hline Rebound & 32 & 3.0 & $0.18(0.12-0.24)$ & 9 & 4.0 & $0.05(0.02-0.08)$ \\
\hline Shot block & 31 & 2.9 & $0.17(0.11-0.23)$ & 10 & 4.5 & $0.06(0.02-0.09)$ \\
\hline Dribbling & 16 & 1.5 & $0.09(0.05-0.13)$ & 0 & 0.0 & $0.00(0.00-0.00)$ \\
\hline Etc. & 6 & 0.6 & $0.03(0.01-0.06)$ & 1 & 0.4 & $0.01(-0.01-0.02)$ \\
\hline Unknown & 63 & 5.9 & $0.35(0.26-0.43)$ & 8 & 3.6 & $0.04(0.01-0.08)$ \\
\hline Total & 1062 & 100.0 & $5.86(5.51-6.21)$ & 223 & 100.0 & $1.23(1.07-1.39)$ \\
\hline
\end{tabular}


- Table 3 Movements generated $>6$ and $8 \mathrm{G}$ during basketball game.

\begin{tabular}{|c|c|c|c|c|c|c|}
\hline \multirow[b]{2}{*}{ Movement } & \multicolumn{3}{|c|}{$>6 \mathrm{G}$} & \multicolumn{3}{|c|}{$>8 \mathrm{G}$} \\
\hline & $\begin{array}{l}\text { Counts } \\
\text { (cases) }\end{array}$ & $\begin{array}{l}\text { Ratio } \\
\text { (\%) }\end{array}$ & $\begin{array}{l}\text { Frequency (cases/min) } \\
95 \% \text { C.I. }\end{array}$ & $\begin{array}{l}\text { Counts } \\
\text { (cases) }\end{array}$ & $\begin{array}{l}\text { Ratio } \\
\text { (\%) }\end{array}$ & $\begin{array}{l}\text { Frequency (cases/min) } \\
95 \% \text { C.I. }\end{array}$ \\
\hline Deceleration & 228 & 21.5 & $1.26(1.09-1.42)$ & 52 & 23.3 & $0.29(0.21-0.37)$ \\
\hline Landing & 81 & 7.6 & $0.45(0.35-0.55)$ & 35 & 15.7 & $0.19(0.13-0.26)$ \\
\hline Cutting & 79 & 7.4 & $0.44(0.34-0.53)$ & 11 & 4.9 & $0.06(0.02-0.10)$ \\
\hline Take-off & 76 & 7.2 & $0.42(0.33-0.51)$ & 19 & 8.5 & $0.10(0.06-0.15)$ \\
\hline Lunging & 47 & 4.4 & $0.26(0.19-0.33)$ & 15 & 6.7 & $0.08(0.04-0.13)$ \\
\hline Sidesteps & 38 & 3.6 & $0.21(0.14-0.28)$ & 9 & 4.0 & $0.05(0.02-0.08)$ \\
\hline Stopping & 37 & 3.5 & $0.20(0.14-0.27)$ & 3 & 1.3 & $0.02(0.00-0.04)$ \\
\hline Physical contact & 22 & 2.1 & $0.12(0.07-0.17)$ & 9 & 4.0 & $0.05(0.02-0.08)$ \\
\hline Etc. & 391 & 36.8 & $2.16(1.94-2.37)$ & 62 & 27.8 & $0.34(0.26-0.43)$ \\
\hline Unknown & 63 & 5.9 & $0.35(0.26-0.43)$ & 8 & 3.6 & $0.04(0.01-0.08)$ \\
\hline Total & 1062 & 100.0 & $5.86(5.51-6.21)$ & 223 & 100.0 & $1.23(1.07-1.39)$ \\
\hline
\end{tabular}

- Table 4 Resultant and directional accelerations (mean \pm SD) among the seven most frequent basketball-specific movements observed $>6 \mathrm{G}$.

\begin{tabular}{|l|c|c|c|c|c|}
\hline $\begin{array}{l}\text { Basketball-specific move- } \\
\text { ments }\end{array}$ & Counts (cases) & Resultant (G) & Mediolateral (G) & Vertical (G) & Anteroposterior (G) \\
\hline $\begin{array}{l}\text { Deceleration during positioning } \\
\text { on the half-court }\end{array}$ & 147 & $7.23(1.14)$ & $1.02(0.74)$ & $6.95(1.86)$ & $1.10(0.80)$ \\
\hline Deceleration during defense & 54 & $7.34(1.09)$ & $1.21(0.82)$ & $6.99(1.16)$ & $1.33(1.03)$ \\
\hline $\begin{array}{l}\text { Cutting during positioning on } \\
\text { half-court }\end{array}$ & 49 & $6.96(0.86)$ & $1.44(0.79)$ & $6.53(0.90)$ & $1.46(0.90)$ \\
\hline Landing during a shot & 43 & $8.21(1.85)$ & $1.03(0.90)$ & $7.70(1.60)$ & $2.10(1.64)$ \\
\hline Lunging during a pass & 26 & $7.48(1.71)$ & $1.73(1.13)$ & $6.95(1.86)$ & $1.30(1.17)$ \\
\hline Sidesteps during defense & 24 & $7.94(2.05)$ & $2.57(2.47)$ & $6.29(3.03)$ & $0.88(2.41)$ \\
\hline Cutting during defense & 22 & $7.20(1.27)$ & $1.47(0.85)$ & $6.81(1.23)$ & $1.56(0.67)$ \\
\hline
\end{tabular}

- Table 5 Two-way ANOVA summary for movements and subjects as factors for each acceleration.

\begin{tabular}{|c|c|c|c|c|c|c|c|}
\hline Variables & Factor & SS & df & MS & F-value & $P$-value & $\eta 2$ \\
\hline \multirow[t]{3}{*}{ Resultant } & Movement (M) & 9 & 6 & 1.48 & 0.7 & N.S. & 0.06 \\
\hline & Subject (S) & 16 & 7 & 2.33 & 1.1 & N.S. & 0.10 \\
\hline & $\mathrm{M}^{*} \mathrm{~S}$ & 92 & 38 & 2.42 & 1.5 & $<0.05$ & 0.15 \\
\hline \multirow[t]{3}{*}{ Mediolateral } & Movement (M) & 26 & 6 & 4.34 & 2.9 & $<0.05$ & 0.24 \\
\hline & Subject (S) & 59 & 7 & 8.48 & 5.9 & $<0.001$ & 0.41 \\
\hline & $\mathrm{M}^{*} \mathrm{~S}$ & 68 & 38 & 1.78 & 2.2 & $<0.001$ & 0.21 \\
\hline \multirow[t]{3}{*}{ Vertical } & Movement (M) & 11 & 6 & 1.91 & 0.6 & N.S. & 0.06 \\
\hline & Subject (S) & 13 & 7 & 1.81 & 0.6 & N.S. & 0.06 \\
\hline & $\mathrm{M}^{*} \mathrm{~S}$ & 140 & 38 & 3.68 & 2.0 & $<0.001$ & 0.19 \\
\hline \multirow[t]{3}{*}{ Anteroposterior } & Movement (M) & 17 & 6 & 2.85 & 1.6 & N.S. & 0.14 \\
\hline & Subject (S) & 30 & 7 & 4.26 & 2.4 & $<0.05$ & 0.22 \\
\hline & $\mathrm{M} * \mathrm{~S}$ & 82 & 38 & 2.16 & 2.0 & $<0.001$ & 0.20 \\
\hline
\end{tabular}

ing a pass"). "Lunging during a pass" was significantly higher than "landing during a shot" ( $p<0.05)$.

\section{Discussion}

This study revealed the frequency and ratio of high-impact movements with greater trunk acceleration during a basketball game. We selected trunk acceleration as a variable indicating external load because it is a reliable measure for GRF [11] and did not prevent upper or lower limb movement during measurements. Because the trunk is the body segment with the highest mass, attaching an accelerometer to it provides the most accurate measure of wholebody acceleration [7]. Our findings show that high-impact movements with greater acceleration mostly involved deceleration and landing, whereas the details of play consisting of high-impact movements were positioning on the half-court, running on the full 
court, and defense. In terms of basketball-specific play, deceleration during positioning on the half-court, deceleration during defense, cutting during positioning on the half-court, landing during a shot, lunging during a pass, sidesteps during defense, and cutting during defense were all detected. Monitoring the frequency and intensity of these details of play and movements could quantify the external biomechanical load.

Deceleration was mostly detected as high-impact movement. According to our results, positioning on the half-court and defense are mostly associated with deceleration. "Positioning on the halfcourt" is mainly the off-ball play during the offense. Deceleration was found to occur frequently during both offensive and defensive play. Decelerations demand intense eccentric and quasi-isometric contractions [19]. Deceleration volumes and intensities define the extent of tissue damage $[20,21]$ and subsequent injury risk [22]. It is thought that coordination or control of loading during deceleration is essential to basketball conditioning.

Landing mostly after a shot was also detected as a frequent high-impact movement. Additionally, the ratio of detected movements increased when the threshold exceeded $8 \mathrm{G}$. The relative duration of movements during a typical basketball game was about $2 \%$ for jumps and $9.3 \%$ for high shuffle movements [1, 23]. Although the ratio of landing after a jump in previous studies [1, 23] was low, a greater ratio was detected than other high-impact movements in this study, particularly in the high resultant acceleration threshold (8G). When a player lands, as they focus on the ball and goal above their head, the acceleration is thought to be greater, because landing in an upright posture increases GRF [24]. Moreover, in volleyball, jumper's knee injuries are caused by repeated load, which occurs mostly during landing [6]. Knee overuse injuries are also common in young basketball players [4]. Therefore, control of loading during the landing phase is important for basketball conditioning, although the frequency of landing was not greater than deceleration.

While comparing the seven most commonly detected basketball-specific high-impact movements in this study, we observed a significant main effect in mediolateral acceleration. The result showed that "side steps during defense" demonstrated higher mediolateral impact, which is a reasonable result assuming the characteristics of sidesteps. However, we also observed a significant interaction, suggesting high inter-player differences. The resultant and directional accelerations further demonstrated the characteristics of a player and not those of movement. It means that a particular player, and not all players, shows high acceleration in a specific movement. Therefore, characteristics of movements or playing style and playing position might have an effect on acceleration patterns during a basketball game. Moreover, these measures might demonstrate the training load or injury risk of each player. In a future study, the relationships between these measures and the player's condition should be examined.

As a practical implication, considering the result of this study, the necessity to control the high-impact load during deceleration and landing is suggested. One way is to decrease the magnitude and frequency of these movements. The impact could be decreased by acquiring more flex posture [24], and injuries may decrease by acquiring this posture with prevention training [25]. Another way is to avoid the sudden increase in loading. Because the increase in the load of acute/chronic ratio is a risk for overuse injury [26], it is necessary to design the practice and game plan such that it does not suddenly increase high-impact deceleration and landing movement.

Despite these results, this study had some limitations. First, we measured movements only in a simulated basketball match from a single team. The level of participants, gender, details of matches, fatigue, or floor material might have effects on acceleration. Second, the present study was a cross-sectional study. To prove the relationship between trunk acceleration and condition, a prospective cohort study is required. It is particularly important to determine which index and threshold are associated with injuries.

\section{Acknowledgments}

The authors would like to thank Enago for the English language review.

\section{Conflict of Interest}

The authors declare that they have no conflict of interest.

\section{References}

[1] Stojanovic E, Stojiljkovic N, Scanlan AT et al. The activity demands and physiological responses encountered during basketball match-play: A systematic review. Sports Med 2018; 48: 111-135. doi:10.1007| s40279-017-0794-z

[2] Clifton DR, Hertel J, Onate JA et al. The first decade of web-based sports injury surveillance: descriptive epidemiology of injuries in us high school girls' basketball (2005-2006 through 2013-2014) and National Collegiate Athletic Association women's basketball (2004-2005 through 2013-2014). J Athl Train 2018; 53: 1037-1048. doi:10.4085/1062-6050-150-17

[3] Takahashi S, Okuwaki T. Epidemiological survey of anterior cruciate ligament injury in Japanese junior high school and high school athletes: Cross-sectional study. Res Sports Med 2017; 25: 266-276. doi:10.1080/15438627.2017.1314290

[4] Leppanen M, Pasanen K, Kannus P et al. Epidemiology of overuse injuries in youth team sports: A 3-year prospective study. Int J Sports Med 2017; 38: 847-856. doi:10.1055/s-0043-114864

[5] Hewett TE, Myer GD, Ford KR et al. Biomechanical measures of neuromuscular control and valgus loading of the knee predict anterior cruciate ligament injury risk in female athletes: A prospective study. Am J Sports Med 2005; 33: 492-501. doi: $10.1177 / 0363546504269591$

[6] Visnes H, Bahr R. Training volume and body composition as risk factors for developing jumper's knee among young elite volleyball players. Scand J Med Sci Sports 2013; 23: 607-613. doi:10.1111/j.1600-0838.2011.01430.x

[7] Vanrenterghem J, Nedergaard NJ, Robinson MA et al. Training load monitoring in team sports: a novel framework separating physiological and biomechanical load-adaptation pathways. Sports Med 2017; 47: 2135-2142. doi:10.1007/s40279-017-0714-2

[8] di Prampero PE, Fusi S, Sepulcri L et al. Sprint running: a new energetic approach. J Exp Biol 2005; 208: 2809-2816. doi:10.1242/jeb.01700

[9] Stevens TG, de Ruiter C], van Niel C et al. Measuring acceleration and deceleration in soccer-specific movements using a local position measurement (LPM) system. Int J Sports Physiol Perform 2014; 9: 446-456. doi:10.1123/ijspp.2013-0340 
[10] Jarning JM, Mok KM, Hansen BH et al. Application of a tri-axial accelerometer to estimate jump frequency in volleyball. Sports Biomech 2015; 14: 95-105. doi:10.1080/14763141.2015.1027950

[11] Simons C, Bradshaw EJ. Do accelerometers mounted on the back provide a good estimate of impact loads in jumping and landing tasks? Sports Biomech 2016; 15: 76-88. doi:10.1080/14763141.2015.1123765

[12] Wundersitz DW, Gastin PB, Robertson S et al. Validation of a trunk-mounted accelerometer to measure peak impacts during team sport movements. Int J Sports Med 2015; 36: 742-746. doi:10.1055/s-0035-1547265

[13] Schelling X, Torres L. Accelerometer load profiles for basketball-specific drills in elite players. J Sports Sci Med 2016; 15: 585-591

[14] Svilar L, Castellano J, Jukic I. Comparison of $5 v 55$ training games and match-play using microsensor technology in elite basketball. J Strength Cond Res. 2018; doi:10.1519/JSC.0000000000002826

[15] Nagano Y, Sasaki S, Higashihara A et al. Gender differences in trunk acceleration and related posture during shuttle run cutting. Int Biomech 2016; 3: 33-39. doi:10.1080/23335432.2016.1191372

[16] Nagano Y, Sasaki S, Higashihara A et al. Movements with greater trunk accelerations and their properties during badminton games. Sports Biomech 2020; 19: 342-352. doi:10.1080/14763141.2018.1478989

[17] Harriss D], Macsween A, Atkinson G. Ethical Standards in Sport and Exercise Science Research: 2020 Update. Int J Sports Med 2019; 40: 813-817. doi:10.1055/a-1015-3123

[18] Tscholl P, O'Riordan D, Fuller CW et al. Tackle mechanisms and match characteristics in women's elite football tournaments. $\mathrm{Br}$ J Sports Med 2007; 41: i15-i19. doi:10.1136/bjsm.2007.036889

[19] Harper D], Kiely J. Damaging nature of decelerations: do we adequately prepare players? BMJ Open Sport Exerc Med 2018; 4: e000379. doi:10.1136/bmjsem-2018-000379
[20] de Hoyo M, Cohen DD, Sanudo B et al. Influence of football match time-motion parameters on recovery time course of muscle damage and jump ability. J Sports Sci 2016; 34: 1363-1370. doi:10.1080/0264 0414.2016.1150603

[21] Young WB, Hepner ], Robbins DW. Movement demands in Australian rules football as indicators of muscle damage. J Strength Cond Res 2012; 26: 492-496. doi:10.1519/JSC.0b013e318225a1c4

[22] Jaspers A, Kuyvenhoven JP, Staes F et al. Examination of the external and internal load indicators' association with overuse injuries in professional soccer players. J Sci Med Sport 2018; 21: 579-585. doi:10.1016/j.jsams.2017.10.005

[23] Ben Abdelkrim N, El Fazaa S, El Ati J. Time-motion analysis and physiological data of elite under-19-year-old basketball players during competition. Br J Sports Med 2007; 41: 69-75. discussion 75. doi:10.1136/bjsm.2006.032318

[24] Shimokochi Y, Ambegaonkar JP, Meyer EG. Changing sagittal-plane landing styles to modulate impact and tibiofemoral force magnitude and directions relative to the tibia. J Athl Train 2016; 51: 669-681. doi:10.4085/1062-6050-51.10.15

[25] Lopes TJA, Simic M, Myer GD et al. The effects of injury prevention programs on the biomechanics of landing tasks: a systematic review with meta-analysis. Am J Sports Med 2018; 46: 1492-1499. doi: $10.1177 / 0363546517716930$

[26] Griffin A, Kenny IC, Comyns TM et al. The association between the acute:chronic workload ratio and injury and its application in team sports: a systematic review. Sports Med 2020; 50: 561-580. doi:10.1007/s40279-019-01218-2 